\title{
Article
}

\section{The Florida State Twin Registry}

\author{
Jeanette Taylor, Kimberly Martinez and Sara A. Hart \\ Department of Psychology, Florida State University, Tallahassee, FL, USA
}

\begin{abstract}
The Florida State Twin Registry has existed for nearly two decades, and it grew primarily over 10 years as part of the Florida Learning Disability Research Center at Florida State University. The registry contains 2753 sets of twins and other multiples in Florida. The mean age of the sample currently is 17.96 years $(\mathrm{SD}=2.05)$. The registry is diverse in terms of race and ethnicity (49\% White, 19\% African American, $24 \%$ Hispanic and $8 \%$ mixed or other). The characteristics of the samples and measures in the studies that served to build the registry are outlined.
\end{abstract}

Keywords: Twin; reading; environment; genetic; personality; behavior problem

(Received 24 May 2019; accepted 26 July 2019; First Published online 5 November 2019)

In 2002, nearly two decades ago, the Florida State Twin Registry (FSTR; Taylor et al., 2006) was created to find participants for a pilot study of personality disorder features and executive functioning in adult twins. A few years later, the Florida Learning Disability Research Center was funded through a center grant from the National Institutes of Health, and the project included the Florida Twin Project on Reading (FTP-R; Taylor \& Schatschneider, 2010). That large-scale twin study of reading provided an opportunity to establish the registry as a database of twins and other multiples in Florida and comprises the current membership of the FSTR. The registry grew a final time through the Florida Twin Project on Reading, Behavior, and Environment (FTP-RBE; Taylor, Hart et al., 2013), which added new twins and brought the registry to a current total of 5593 members that are mostly in twin pairs, although there are other multiples. Recruitment and data collection were completed on that study in 2017. However, twin research continues as part of the Florida Learning Disability Research Center grant with the National Project on Achievement in Twins (Hart et al., 2019, this issue), which focuses on reading and math co-development.

\section{Overview of Samples and Measures in the FSTR}

The FSTR is the repository of contact information for the many twins and multiples who have agreed to be alerted to research opportunities offered by the registry's creator (J.T.) and her collaborators. Current membership of the FSTR is described in Table 1. Some samples that have been used for specific studies have been described elsewhere (Taylor et al., 2006; Taylor et al., 2013), but a brief recap of each sample is provided here.

\section{Pilot Study of Personality Disorders}

The pilot project that was the impetus for starting the FSTR focused on personality disorders and executive functioning in adults (Taylor et al., 2006). Twins were identified with help from

Author for correspondence: Jeanette Taylor, Email: taylor@psy.fsu.edu

Cite this article: Taylor J, Martinez K, and Hart SA. (2019) The Florida State Twin Registry.

Twin Research and Human Genetics 22: 728-730, https://doi.org/10.1017/thg.2019.102 staff in the registrar's office at Florida State University. Students enrolled at the university who matched on last name, birth date, and hometown were considered potential twin-pairs and were contacted about the study. Newspaper advertisements also attracted adult pairs from the community. The pilot study sample included 81 monozygotic (MZ) pairs (22 male) and 27 same-sex dizygotic (DZ) pairs (4 male) with a mean age of 23.76 year $(S D=11.68)$. Contact was not maintained with the adult twins given the focus of the subsequent studies on school-aged twins. As such, the adult twins are not included in the current FSTR.

\section{Florida Twin Project on Reading}

Nearly all members of the FSTR are part of the FTP-R sample. The FTP-R (see Taylor \& Schatschneider, 2010; Taylor, Hart et al., 2013) was aimed at examining reading achievement over 5 years in early elementary school, which at the time was a segment of reading development not covered by other twin studies. Twins were ascertained using student information in Florida's Progress Monitoring and Reporting Network (PMRN), a statewide database of standardized achievement tests administered in schools. Specifically, potential twins were identified by matching children within schools in Florida on last name, birth date, and grade. Parents of potential twins were mailed a postcard assessing zygosity with a five-item questionnaire (Lykken et al., 1990) and obtaining permission to include their twins' achievement data from the PMRN in the FTP-R. The FTP-RBE study (described below) added new twins using this same method, and parents of those new twins gave permission to use the twins' PMRN data, so those pairs became part of the FTP-R sample. Membership of the FSTR is described in Table 1, and this reflects the FTP-R sample as well.

The PMRN database served as the sole data source for the FTP$\mathrm{R}$ and included Dynamic Indicators of Basic Early Literacy Skills (DIBELS) scores for several measures, including Letter Naming Fluency, Initial Sound Fluency, Phoneme Segmentation Fluency and Oral Reading Fluency. The DIBELS measures were discontinued in Florida in 2009 and were replaced with measures of reading fluency, comprehension and spelling contained in Florida's 
Table 1. Florida State Twin Registry membership

\begin{tabular}{lccc}
\hline & MZ & DZ & Total \\
\hline Male pairs $(N)$ & 444 & 486 & 930 \\
\hline Female pairs $(N)$ & 462 & 457 & 919 \\
\hline Opposite-sex pairs $(N)$ & - & 824 & 824 \\
\hline Male triplet sets $(N)$ & 6 & 7 & 13 \\
\hline Female triplet sets $(N)$ & 7 & 5 & 12 \\
\hline Opposite-sex triplet sets $(N)$ & 6 & 40 & 46 \\
\hline Quadruplet sets (N) & - & 2 & 2 \\
\hline Unknown zygosity pairs/sets & - & - & 7 \\
\hline Total & 925 & 1821 & 2753 \\
\hline White (\%) & 45 & 50 & 49 \\
\hline African American (\%) & 17 & 20 & 19 \\
\hline Hispanic (\%) & 28 & 22 & 24 \\
\hline Mixed/other (\%) & 10 & 8 & 8 \\
\hline Mean current age (SD) & $17.91(2.11)$ & $17.99(2.02)$ & $17.96(2.05)$ \\
\hline
\end{tabular}

Note: Both of the quadruplet sets are opposite sex. Unknown zygosity was due to missing data on the parent-rated zygosity questionnaire. The current age range across all registry members is $11-22$ years.

custom-designed assessment called the Florida Assessments for Instruction in Reading (Florida Department of Education, 2009-2010). The PMRN also provided scores on the annual statemandated standardized test, the Florida Comprehensive Assessment Test on Reading (Florida Department of Education, 2001), which was updated in 2014 and renamed the Florida Standards Assessments (Florida Department of Education, 2014-2015). PMRN data were available to the researchers only through the 2013-14 school year.

\section{Florida Twin Project on Behavior and Environment}

In summer 2010, families of same-sex twins in the FTP-R were recruited into a study aimed at examining reading as it related to certain behaviors and to the home environment. A packet of questionnaires was sent to all parents to complete about their twins, and twins aged 9 and older were sent a separate packet of questionnaires. A total of $362 \mathrm{MZ}$ (186 female) and 351 samesex DZ (170 female) pairs comprised the sample. The mean age at the time of study completion was $9.52(\mathrm{SD}=1.78)$.

The parent packet of questionnaires included measures of the twins' personality, childhood psychological disorders such as attention-deficit/hyperactivity disorder, and anxiety and depression. Parents also answered questions about the home literacy environment, parental marital status and family income. Twins completed measures related to their personality, anxiety about school and characteristics of their friends.

\section{Florida Twin Project on Reading, Behavior and Environment}

The Florida Learning Disability Research Center grant was renewed in 2012, and the FTP-RBE was part of it (Taylor, Hart et al., 2013). That project built on the results from the FTP-R and the Florida Twin Project on Behavior and Environment (FTP-BE) and examined reading as it related to executive functioning, behavior problems and home and school environment over three assessments spaced 2 years apart. New families with twins in grades $\mathrm{K}-3$ were recruited using the same method as was used in the FTP-R, and those new families agreed to became part of both the FTP-RBE sample and the FTP-R sample. A total of $446 \mathrm{MZ}$ (238 female), 242 same-sex DZ (137 female) and 103 oppositesex DZ pairs comprised the final FTP-RBE study sample with data on at least the first of three waves. The mean age of the sample at Wave 1 was $11.37(\mathrm{SD}=2.49)$.

Parents and twins aged 9 and older were mailed questionnaires to complete. Taylor, Hart et al. (2013) provide a listing of measures in the FTP-RBE's Wave 1 assessment. Briefly, the parents reported on their twins' home environment and neighborhood characteristics, and on the twins' personalities, symptoms of childhood behavioral disorders, executive functioning and school grades. Twins reported on their classroom environment, grades, personality and characteristics of their friends. Twins completed a narrative writing prompt (McMaster et al., 2009) and vocabulary and reading comprehension subtests from the Gates-MacGinitie Reading Tests (MacGinitie et al., 2000) at home under the supervision of a parent who was provided detailed instructions on test administration. The assessments for Wave 2 and Wave 3 were changed such that measures showing no association with reading outcomes in Wave 1 were dropped (e.g., amount of time parent spent reading to the twins), age-appropriate new measures hypothesized to be related to reading achievement were added (e.g., video game preferences and time spent playing; use of electronic devices for school and leisure), and the battery of reading measures completed at Wave 3 was shortened.

\section{Summary of Key Findings}

The FSTR has produced datasets on a variety of phenotypes and environments that will continue to be used to address important questions, but some key findings have already emerged. The original pilot project from the FSTR showed that a neuropsychological test that was thought to be a possible endophenotype for schizophrenia was not actually heritable when examined in nonclinical young adults (Taylor, 2007). The FTP-R study that greatly expanded the headcount in the FSTR and focused on reading data from schools was large enough to address questions of geneenvironment interplay and genetic and environmental effects on longitudinal data. For instance, Taylor et al. (2010) showed that 'teacher quality' as defined by performance of twins' classmates on reading fluency over the course of first grade moderated genetic influence on reading fluency. Specifically, twins in lower quality classrooms showed less genetic influence on their oral reading fluency, suggesting that lower performing environments may dampen the influence of genes and possibly hinder a student from reaching his/her potential. Conversely, genetic influence was higher for twins in higher performing environments, suggesting that better quality environments allow children to flourish. The FTP-R data were also used to show that shared genetic influences are at work in explaining variability in reading from Grade 1 through Grade 5, but the first three grades also show novel genetic influences (Hart et al., 2013). Shared environmental influences were shown to be stable over the first 5 years of school.

The FTP-BE and FTP-RBE studies brought in data on child behavior and aspects of the home environment. These data have yielded new insights on everything from the nature of the association between externalizing problems and socioemotional dispositions (Taylor, Allan et al., 2013) to using geocoding to better understand how the neighborhood environments around children are associated with reading performance (Little et al., 2019). 


\section{Future Directions}

Future studies using the FSTR will need to shift toward questions relevant to young adulthood. Many of the twins are now in middle school, high school or have graduated, making this registry well suited to studying important aspects of the transition into college, work life, marriage and even parenthood. Researchers who are interested in possible collaborations should contact the first author.

Acknowledgment. This article was supported in part by the Eunice Kennedy Shriver National Institute of Child Health \& Human Development grant HD052120.

\section{References}

Florida Department of Education. (2001). FCAT handbook-A resource for educators. Tallahassee, FL: Author.

Florida Department of Education. (2009-2010). Florida assessments for instruction in reading. Tallahassee, FL: Author.

Florida Department of Education. (2014-2015). Florida Standards Assessments. Tallahassee, FL: Author.

Hart, S. A., Logan, J. A. R., Soden-Hensler, B., Kerhshaw, S., Taylor, J., \& Schatschneider, C. (2013). Exploring how nature and nurture affect the development of reading: An analysis of the Florida Twin Project on Reading. Developmental Psychology, 49, 1971-1981.

Hart, S. A., Martinez, K., Kennedy, P. C., Ganley, C. M., \& Taylor, J. (2019). The National Project on Achievement in Twins. Twin Research and Human Genetics. Advance online publication.
Little, C. W., Hart, S. A., Phillips, B., Schatschneider, C., \& Taylor, J. (2019). Exploring neighborhood environmental influences on reading comprehension. Journal of Applied Developmental Psychology, 62, 173-184.

Lykken, D. T., Bouchard, T. J. Jr, McGue, M., \& Tellegen, A. (1990). The Minnesota Twin Registry: Some initial findings. Acta Geneticae Medicate at Gemellologiae: Twin Research, 39, 35-70.

MacGinitie, W., MacGinitie, R., Maria, K, \& Dreyer, L. G. (2000). GatesMacGinitie Reading Tests (4th ed.). Itasca, IL: Riverside.

McMaster, K. L., Du, X., \& Petursdottir, A. L. (2009). Technical features of curriculum-based measures for beginning writers. Journal of Learning Disabilities, 42, 41-60.

Taylor, J. (2007). Heritability of Wisconsin Card Sorting Test (WCST) and Stroop Color-Word Test performance in normal individuals: Implications for the search for endophenotypes. Twin Research and Human Genetics, 10, 829-834.

Taylor, J., Allan, N., Mikolajewski, A. J., \& Hart, S. A. (2013). Common genetic and nonshared environmental factors contribute to the association between socioemotional dispositions and the externalizing factor in children. Journal of Child Psychology and Psychiatry, 54, 67-76.

Taylor, J., James, L., Reeves, M., \& Bobadilla, L. (2006). The Florida State Twin Registry: Research aims and design. Twin Research and Human Genetics, 9, 958-962.

Taylor, J., Roehrig, A. D., Hensler, B. S., Connor, C. M., \& Schatschneider, C. (2010). Teacher quality moderates the genetic effects on early reading. Science, 328, 512.

Taylor, J., \& Schatschneider, C. (2010). Genetic influence on literacy constructs in kindergarten and first grade: Evidence from a diverse twin sample. Behavior Genetics, 40, 591-602.

Taylor, J. E., Hart, S. A., Mikolajewski, A. J., \& Schatschneider, C. (2013). An update on the Florida State Twin Registry. Twin Research and Human Genetics, 16, 471-475. 